\title{
Los no contactados: Una mirada desde tres entrevistas
}

Teodoro Bustamante dinámica cultural en esta región, contribuyendo a que esa reflexión se relacione y forme parte de un proceso mayor de construcción y sofisticación de la disciplina en su conjunto. Ane Christine, acaba de jubilarse de su cargo en el museo de Quai Branly; Laura tiene tareas docentes en el London School of Economics; mientras que, Marcelo lleva ya sobre sus hombros una larga y fructífera carrera de formación en la Universidad Católica de Quito.

Nos propusimos recoger los puntos de vista de estos tres académicos a través de una entrevista. Con Marcelo y Ane Christine fue posible efectuar la entrevista personalmente. Con Laura, en cambio fue necesario usar los recursos del internet.

Las tres entrevistas contienen preguntas y respuestas críticas. A los tres les preguntamos sobre su perspectiva en relación a la situación, los esfuerzos que se están desarrollando y los tres nos respondieron con un apreciable nivel de criticidad. No nos dejan mucho espacio para la complacencia. La sociedad ecuatoriana y también la antropología que en ella realizamos, tiene deudas con el proceso social del cual nos ocupamos. Pero ojo, no se trata de identificar algunos errores y señalar alguna solución sencilla que pudiera constituir la alternativa para todo. Las críticas que nos formulan no se refieren a problemas puntuales y específicos. Se refieren a la necesidad de madurar procesos para tratar estos problemas, acumular esfuerzos, experiencia y también reflexionar sobre como la dinámica que viven los pueblos en aislamiento nos cuestiona como sociedad y como profesión.

Nos lanzan también advertencias, el conocimiento antropológico no nos sirve para encontrar soluciones fáciles, y con cierta insistencia nos indican la necesidad de mantener la independencia de la reflexión académica de las necesidades de gestión política inmediata. Usar los aportes sobre las ontologías amazónicas para intentar resolver estos temas puede ser irrelevante, pues es necesario atender y comprender antes procesos mucho más cercanos a las interacciones con sociedades, Estados y economías en expansión.

En esta revista, donde se ha buscado dar un espacio sobre todo a quienes reflexionan y abordan estos temas desde el Ecuador, proponemos esta serie de entrevistas como un complemento que aporta miradas desde distancias geográficas (Paris, Londres) y temporales, tomando en cuenta que Marcelo Naranjo fue una de las primeras personas que trabajó sobre esta región. 
No está demás agregar que esta lista de tres personas, no pretende en ningún caso ser completa. Sería muy enriquecedor recoger otras miradas que desde fuera o desde el interior del país tienen ricas trayectorias, y una reflexión armada sobre esta realidad.

Queremos insistir aquí nuestro reconocimiento por la ayuda recibida y por el tiempo que estos colegas nos otorgaron. Veamos ahora lo que estas entrevistas nos traen.

\section{Marcelo Naranjo*}

Doctor Naranjo, usted fue uno de los primeros antropólogos ecuatorianos con formación académica que trabajó cerca de la zona donde hoy se encuentran los pueblos no contactados. ¿En qué medida considera usted que lo que se vive en la actualidad respecto a estos pueblos, es una continuidad o una ruptura respecto a lo que usted vivió varias décadas atrás?

Bueno, yo considero que existe una continuidad, pero que en esa continuidad los problemas se van agravando, porque cuando nosotros estuvimos por allí, la temática de estos pueblos no contactados todavía no era conflictiva, pero ahora ha pasado a ser una problemática altamente conflictiva, porque hay varios grupos con diversas perspectivas e intereses que, o tratan de cortar el acercamiento con dichas sociedades, o que pretenden favorecerlo; de igual modo, también se plantea qué beneficios puede sacar cada quien si es que les contacta, o no. Allí estaban, y, en cierto sentido constituían un problema por su violencia entiéndase por violencia su actitud frente a la cada vez más escasa disposición de recursos para su sobrevivencia biológica y socio cultural, típica de pueblos amazónicos, como por ejemplo los Yanomamis. Pero ahora hay muchos contendientes detrás de estos grupos y cada uno quiere sacar partido, diría yo, de su posibilidad de contacto o no contacto con estas sociedades.

Ahora la situación para mí es mucho más grave que al principio, y es todavía más grave con los propios (con los ya contactados), porque de lo que se sabe (aunque de esto no se sabe mucho) son de los propios wao los que arman las incursiones hacia los territorios de los no contactados. En resumen, hay una continuidad relativa a la temática general, pero un agravamiento en la centralidad del problema.

Tendríamos entonces, que el fenómeno en sus dimensiones es nuevo, sobre bases pre-existentes.

Exactamente, y mucho más grave, porque lo que no se toma en cuenta, o no se quiere tomar en cuenta, es que está la vida de las personas de lado y lado.

Pasemos a otra pregunta. Hace algunos años, usted realizó un análisis de los refugios étnicos en la Amazonía, y en particular el caso de los kichwas. ¿Considera usted que la actual situación de los pueblos aislados coincide, cabe dentro de estas ideas de los refugios étnicos?

Yo pensaría que no. Creo que las condiciones históricas en las cuales han vivido estos pueblos han sido bien diferentes. En el análisis que yo hacía algunos años atrás, estaba claramente documentado, por la información que se tenía, de carácter etnohistórico, que hubo una motivación migracional y un deseo absolutamente consciente de buscar un alejamiento y un enclave dentro del cual puedan llevar adelante su proceso de vida. Eso hicieron los kichwas a su tiempo; hay evidencias muy sólidas que nos permiten demostrar que ellos se movilizaron de la serranía y se fueron para allá, a la ceja de montaña.

* PHD. Antropólogo cultural por la Universidad de Illinois. Profesor principal en la PUCE. Ha realizado investigaciones en la región amazónica ecuatoriana. 
Yo creo que aquí no es una idea programada de los no contactados de constituirse en una zona de refugio, sino que están allí, porque hasta allí han podido llegar. Una de las cosas que hay que tomar en consideración, a través del cuidadoso análisis de la etnohistoria de los wao, es que ellos han tenido que afrontar cambios dramáticos por la fortísima presión demográfica que ha habido en la Amazonía, muy acentuada desde el siglo XIX. Por ejemplo, no siempre se reconoce el hecho de que ellos históricamente fueron pueblos inter-fluviales y ahora son fluviales, lo cual significa un cambio drástico en usos, costumbres, en posibilidades de vida, etc. Entonces, ellos más o menos se van ubicando donde las circunstancias les permite estar. Toda esta zona de Cononaco-Bameno, donde están ahora más o menos "refugiados", es hasta donde se le ha permitido llegar, y donde han podido mantenerse medianamente ocultos. Pero siempre respondiendo, como una acción reactiva y no proactiva. En la Amazonía las cosas son mucho más complicadas.

En la historia del pueblo waorani, hay una fuerte marca de la violencia y la guerra. Desde las perspectivas de las misiones religiosas, tanto católicas como evangélicas en sus diferentes momentos, se vio la necesidad de una intervención para mejorar la situación wao, con los resultados ya conocidos. ¿En la actualidad considera que es necesaria una intervención externa para evitar que las muertes continúen en el territorio Wao?

Sólo la palabra 'intervención' ya me pone nervioso. Sencillamente cuando estamos hablando de intervención, estamos hablando de forzar voluntades y desde qué perspectiva este planteamiento es ético. Todas las experimentaciones, de buena o de mala voluntad (o de mediana voluntad), hechas por las misiones religiosas, han tenido un costo bien grande para los pueblos nativos, eso ya sabemos. También me parece un facilismo pensar que si intervenimos va a terminar la violencia. No, por el contrario, yo creo que si intervenimos, en cierto sentido, se va a exacerbar la violencia, porque uno de los problemas de la violencia, cuando se traduzca en intervención, será tratar de decir "ustedes tienen que ser así o tienen que asimilarse a, no pueden seguir siendo lo que han sido siempre", y eso ya es violencia y podría generar múltiples reacciones, muchas de ellas violentas.

Entonces, yo creo que aquí vivimos una paradoja, ¿Qué hacemos? Nos cruzamos de manos y decimos bueno, que "el destino", si es que existe el destino, dicte lo que va a suceder, o cuáles son las estrategias que en cierto sentido se podrían dar, de cara a que este cambio inexorable que van a tener que pasar, se dé con el menor costo. ¿Pero quién va a hacer eso?, ¿va a ser el Estado ecuatoriano?, ¿van a ser ciertas ONGs?, ¿van a ser los propios wao del otro lado?, ¿quiénes van a dar esos pasos en primer lugar? En un análisis costo - beneficio, ¿costo y beneficio para quién?, ¿desde quién?, también esa es otra importante consideración que deberíamos plantearnos. Todos los efectos que podrían seguirse de esta intervención, en términos de salud, de ocupación, interrelación, de la vida misma no son claros, desde ningún punto de vista alguno. En definitiva, se debería pensar qué sucederá si llegamos a intervenir, y cuáles serán los costos de tal acción, evidentemente dichas consideraciones son fundamentales y sobre las cuales deberíamos reflexionar.

Yo creo que sobre este tema amerita un gran consenso, un gran debate en el cual más o menos se trate de vislumbrar puntos determinantes que podrían eventualmente ayudar a que el paso sea menos costoso. Por ejemplo, esto del cerco epidemiológico. A mí me parece que es interesante, es interesante porque si tomamos experiencias pasadas, por ejemplo, la del "protectorado" que hicieron los evangélicos en la comunidad de Toñanpari (en los años 50's - 60's), tuvo muy graves consecuencias, ¿qué es lo primero que pasó? Una de las cosas más dramáticas que sucedió fue el gran problema de la poliomielitis, por el cual murieron muchos waos y otro significativo grupo quedaron lesionados para toda la vida. Entonces, el primer contacto, o un contacto ya más sistemático, uno de los primeros problemas que tiene que tomar en cuenta es ese. Vamos a tener que afrontar un problema médico severo, absolutamente severo. Medidas como esas tendrán que ser conversadas, comentadas y tratar de alcanzar elementales consensos. 
Pero yo veo que aquí casi hay un "derecho de propiedad" respecto de los Waos. O el Estado está pugnando por decir: "los wao son del Estado y concomitantemente solo el gobierno de turno, sería el encargado de tomar las decisiones"; o ciertas ONGs con determinados intereses se arrogan el derecho de manifestar: "nosotros somos los que tenemos que hacer"; del mismo modo, las organizaciones religiosas, independientemente de su filiación, plantean: "nosotros vamos a hacer". ¿Por qué no nos reunimos todos, nos sentamos, y un momento determinado comenzamos a lanzar un poco de ideas y tratamos de sistematizar acuerdos básicos? Eso es lo que yo veo, y me desespera que no hay dicha actitud. Como si todo lo manifestado sería poco, también hay ciertos antropólogos/as, o ciertas personas con un aire de Indiana Jones y en actitud patética plantean: "yo me voy a conquistarles a estas personas y no importa que yo dejé mi vida en camino". Es obvio que no se trata de eso, el heroísmo aquí no cuenta; aquí lo que cuenta es una racionalidad, pero siempre tomando una perspectiva de qué es lo que va a pasar para ellos. Ese es uno de los problemas pero realmente graves.

Ahora podríamos ahí hacer una pregunta, porque el problema de salud es un problema muy importante en el contacto, y casi todos los registros muestran que luego del contacto hay una crisis epidemiológica fuerte. Ahora también hay otra cosa que es clara, y es que después de superado eso, en el caso de los Wao, éstos han tenido una recuperación demográfica muy clara. Lo que en algún momento se temió que se extinguieran por enfermedad, en este momento parece que no va a suceder, ellos han tenido una recuperación demográfica, en los últimos 30 - 40 años han duplicado su población, o más. Entonces ahí vemos los dos lados de la intervención: el riesgo, pero también el hecho de que pueda haber, digamos aspectos positivos, es decir, la recuperación demográfica es un aspecto que podría ser considerado como positivo, ¿no?

Sí, en las estadísticas eso suena bien, pero, lo que tendríamos que preguntarnos un poco antes es: ¿Qué les ha permitido este repunte demográfico?, muy probablemente el abandono de su modo tradicional de vida, y eso también tienen severos costos: ideológicos, culturales, visión del mundo, organización socio productiva, etc., etc.

¿Quiénes son las familias que han logrado llevar adelante un proyecto de vida contando con cuatro o cinco hijos?, quienes se han enchufado directa o indirectamente con petroleras, con madereras, etc.; quienes han cambiado drásticamente su modo de vida y comienzan a pugnar dentro de la ecuación: recursos y posibilidades. Pero el momento en que estos no contactados, entre comillas "no contactados", quieran tomar esa opción, les va a tomar un largo camino para eso. Para comenzar por lo más sencillo, el aprendizaje de un idioma como el español, que les es absolutamente extraño a ellos. Entonces sí, podría haber y de hecho están ahí los registros de la recuperación demográfica de los Wao, ¿pero a costo de qué?, de cambiar su propio modelo de vida.

Cuando nosotros aludimos a las sociedades de foresta tropical tradicionales, de cazadores y recolectores, les estamos implicando a ellos, ya que son ellos quienes mantienen esa modalidad de vida, pero los otros, los demás ya no. Pero en este paso terriblemente grande y traumático de asumir a un sistema de vida diferente, van a saltar las alarmas y se van a quemar los fusibles de un montón de situaciones, con proyecciones impensadas, y eso es muy grave.

\section{Lo cual indicaría que el problema no es de soluciones fáciles.}

Obviamente, en modo alguno.

Y bueno, aquí estamos viendo un poco las cosas que suceden, y tal vez una de las perspectivas más interesantes que usted puede aportar es la profundidad temporal, es decir, usted no ha recorrido la zona desde hace dos o tres años, y no me acuerdo cuántos años son, pero 
son décadas. A partir de esa mirada con cierta profundidad temporal ¿Cuáles son las cosas que usted consideraría más importantes de ese pasado que se deben tener en cuenta para entender lo que pasa hoy?

Bueno, yo creo que hay muchas cosas. Uno de los problemas, desde mi perspectiva, que ahora se confronta es la crisis de liderazgo al interior del grupo. Los Nanicabos estaban organizados en función de una jerarquización etaria, los viejos eran los que decidían. Los viejos siempre decidieron dónde estar, qué hacer, cómo se daban los intercambios, etc. Con la irrupción de los jóvenes que se van integrando de mejor manera en el mundo que les rodeaba, se produjo una verdadera crisis de liderazgo al interior del grupo, porque es cierto que existen organizaciones formales de los Wao, pero en el momento de las decisiones trascendentales sigue habiendo un conflicto generacional por el liderazgo, y es una de las cosas que se tiene que retomar. El liderazgo tradicional dentro de Nanicabo históricamente estuvo dado por los viejos, y los viejos todavía están pugnando por eso, y hay seria conflictividad respecto de ese problema.

Entonces esa es una de las lecciones que yo creo que debemos aprender, de que el proceso de negociación no se puede hacer exclusivamente con estas organizaciones nacidas al contacto de las asociaciones tipo ONHAE, etc. porque la profundidad en la estructura del poder en esas sociedades es bien diferente y eso va creando conflictividades. Yo he estado en algunas de las comunidades más tradicionales de ellos, que dicho sea de paso, son comunidades que sí han estado en contacto con los "no contactados", ellos saben dónde están y cuándo van y cuándo dejan de ir a verles, etc. Pero en esas comunidades realmente se puede ver de una forma muy clara y muy explícita, quién mantiene el poder. Entonces para ellos les es terriblemente chocante, por decirlo de alguna manera, el que las negociaciones o que las decisiones sean dadas por estas organizaciones tan pobladas de la gente nueva, de la gente jovencita que realmente no representa esa estructura tradicional. Con esto no quiero decir que haya que prescindir de los jóvenes, pero hay que darse cuenta de cómo es la pirámide de liderazgo al interior de estas sociedades si no queremos llegar a cambios absolutamente drásticos e indeseados.

Ahí se ha visto algunas posiciones, que se han dado, entre los viejos Waos, que decían: "no a la intervención, no al contacto con esto, no vamos a trabajar con las petroleras, no vamos a trabajar con los kugure. No queremos trabajar con los kugure, lo único que queremos es que nos dejen vivir acá en paz, y punto". Pero los jóvenes inmediatamente venían con la tesis: "no, es que vamos a tener dinero para hacer esto, esto y aquello, etc.,". Entonces es un enfrentamiento de visiones de mundo, una visión del mundo que está absolutamente adherida a ese pasado específico, de muchas maneras conflictivo, porque tampoco se puede decir que los Wao vivieron en un paraíso. No, es una sociedad violenta porque les ha tocado vivir condiciones estructurales violentas, de naturaleza endógena y exógena, frente a los cuales han respondido. Los Wao por aquí; son los Yanomamo en Venezuela, sociedades que para su sobrevivencia tuvieron que desarrollar ese tipo de estrategias, no le quedó otro camino. Pero entonces, aquí en la problemática de los pueblo "no contactados" lo que en cierto sentido se está planteando es cómo se daría el paso a la modernidad o dejamos de dar el paso a ella, de quién nos asimos para dar este paso, quiénes van a ser los pilares de esta nueva sociedad, qué van a ganar o qué van a perder con esto.

También podría plantearse una situación intermedia, es decir, cómo convivimos con grados de autonomía determinados que no impliquen riesgos ni total aislamiento, que exista la posibilidad de moverse a la modernidad cuando se lo desee, como se lo quiera y al paso que se quiera.

Exactamente. 


\section{¿Es eso posible?}

A eso iba. Eso se puede manifestar como un planteamiento ideal, pero ahí comenzamos a enfrentarnos con problemas tan tangibles y concretos como la territorialidad. Si yo, en este paraíso perdido, podía tener este modelo de vida, esas condiciones ya no se podrán dar, nos guste o nos deje de gustar. Por comenzar, el modelo de cazador - recolector está agotado o ha sido reducido a su mínima expresión. Entonces, si ellos contarían con un territorio suficientemente extenso para que les permita este modo de vida, se podría decir sí, que ellos vayan dando el cambio si quieren dar cambio a su ritmo, pero esas condiciones ya no se dan. Ya no podemos sacar a los colonos, ya no podemos sacar a las empresas, ya no podemos sacar un montón de circunstancias exógenas que están interviniendo. Entonces sí, nos avocamos a un cambio, pero desde qué punto de vista y con qué costos y con qué estrategia.

A pesar de que probablemente usted ya ha señalado cosas respecto a esta pregunta, la formulo nuevamente. Sería pedirle a usted que nos indique: ¿Qué cree usted que son los mayores errores que se pueden cometer al tratar de explicar la realidad de los pueblos no contactados? ¿Qué errores habría que editar?

Yo ya mencioné uno. A mí realmente me espeluzna el que se ha convertido en varias instancias, tanto oficiales como no oficiales, en la gran aventura: el contacto con los no contactados. Por eso yo le decía, ya hay un montón de gente con el "uniforme de Indiana Jones". Yo voy a llegar porque yo soy valeroso, porque yo soy valiente, porque yo soy audaz y a pesar de todo, voy a llegar allá. Esa no es la forma de llegar, y eso se ha dado y se va a dar. Entonces, más o menos abandonar ese espíritu aventurero o, desde otro punto de vista, tampoco ir con el sentimiento de que como yo estoy prevalido de cosas religiosas, Dios me va a proteger, porque eso tampoco se da y ya lo hemos visto.

Yo creo que aquí es fundamental en este contacto eventual o necesario, impostergable o inexorable, como se quiera decir, el tomar como punto de contacto a la propia sociedad de los viejos Wao, que son los que pueden dar tiempos, que son los que pueden dar lugares, que son los que pueden dar una serie de elementos fundamentales que permitan establecer el contacto. Es decir, no acciones individualistas, por ganar una serie de éxitos, entre comillas, y por llevarse el premio de nosotros fuimos los que; no, sino que el camino es a través de ellos mismos, como ya he manifestado. Por ejemplo en Cononaco - Bameno, los viejos de esa comunidad se reúnen con los no contactados por lo menos una vez cada mes y eso es secreto a voces, y no hay muertes ni mucho menos porque saben en lo que están. Cruzan el río y ahí están, ahí les van a encontrar, ahí tienen encuentros. Esta gente tiene que jugar un papel fundamental, en este tipo de acciones.

\section{Pero un papel fundamental que no sea de instrumentos para lo que usted ha llamado aventuras a lo Indiana Jones}

Obviamente, por eso decía que ellos van a dar temas, ellos van a dar espacios, ellos va a dar tiempos, ellos van a decir qué está esperando esta gente. Entonces, en función de esa información se podría decir bueno, si esas son las perspectivas de esta gente, vamos a tratar de acomodar un escenario que en cierto sentido responda a las expectativas de ellos. Entonces eso me parece que es una de las cosas que nosotros no podemos olvidar, no se tiene que seguir con este tipo de aventuras. Es que yo veo cada vez que voy por esas zonas, me espeluzna eso. Es casi, casi como la aventura de ir de Safari, y no puede ser así.

Yo sacaría de lo que escucho, Marcelo, la recomendación de que esto no se lo debe convertir en una aventura personal; segundo, la necesidad de no subordinarlo a luchas faccionales de quiénes son los redentores de los Waorani o de los no contactados. 
Redentores, pacificadores, los defensores, como queramos llamarlo. Yo pienso sobre todo, para las personas más jóvenes, que por $x$ motivo tengan que ver con esto, ¿qué otra advertencia?

Mire, yo creo que es fundamental, yo he tenido conversaciones largas con viejos al respecto. Todavía sigue un elemento conflictivo muy, muy grande, que es el intercambio de mujeres. Muchas veces este es el problema central. Entonces, hay que considerar que hay toda una estructura social que todavía subyace por ahí. El contacto, el intercambio de mujeres es un motivo de conflictividad. Tomar en consideración ese tipo de cosas, no estoy diciendo que debamos aproximarnos a ellos como un caso para poner en práctica las teorías antropológicas sobre parentesco, pero hay realidades que ellos todavía viven. Uno tiene que estar consciente de que esas realidades todavía se dan y que es una de las cosas que también hay que tomar en consideración. No es cuestión de decir, les vamos a sacar, les vamos a poner en un pueblo a vivir, les vamos a dar los primeros 15 años los elementos suficientes como para que ellos sobrevivan. No, no se trata de eso, se trata de reproducir en cierta escala modelos de vida acoplados a una nueva realidad, pero a fin de cuentas, modelos de vida propios. Esa es otra de las cosas que hay que tomar muy, muy en consideración.

\section{¿Alguna otra cosa antes de cerrar?}

Yo te diría que desde mi punto de vista hay dos o tres focos de donde salen las noticias y que se las va distorsionando y eso genera problemas: uno es el producido desde la capital, que mantiene esa visión errática que todavía tenemos de los Wao y de los no contactados; otra es la visión que se tiene ya en las regiones cercanas allá, donde se va desde el miedo - pánico, hasta la incomprensión total; y la tercera visión cuya fuente son ellos mismo. Entonces yo veo que en estos diversos niveles hay unas contradicciones enormes, si yo desde acá tengo una visión, entonces yo como "planifico", voy a planificar una cosa que no tiene asidero en una realidad que se vive en su lugar de origen. Si yo respondo a los miedos, fundamentados o no, voy a planificar de otra manera; y si yo me apego a una visión sesgada de ellos mismos, respecto a la naturaleza de los problemas, igualmente, será diferente y eso quiere decir que no nos estamos entendiendo $\mathrm{y}$, concomitantemente el problema nunca lo vamos a resolver.

Tienen que quebrarse un montón de estereotipos, un montón de falsas ideas y de falsas concepciones. Al fin y al cabo, también son seres humanos, y en su condición de tales tienen un montón de semejanzas con nosotros, por más "exóticos" que puedan aparecer. Pero las soluciones y los contactos y todo lo concerniente a su vida no requiere de la creación de un meta - lenguaje para llegar a ellos. Con un poco de racionalidad, un poco de conocimiento, yo creo que se pueden hacer cosas, pero no tratando de sacar rédito político o rédito económico, o rédito académico de estas cosas, sino con un acercamiento de una perspectiva fundamentalmente humana.

De alguna manera entre toda tú exposición, Marcelo, aparece un problema de legitimidad. De una legitimidad para acercarse, para manejar el contacto, que tienen que ver con unos valores para hacerlo. Tú estás señalando que aquí se necesita un sentido humano y casi parecería, no sé si te interpreto bien, que tú estás diciendo que hay que darles suficiente espacio a los valores humanos sobre los intereses particulares que se desenvuelven en torno a esto.

Sí, mira, ahora que estábamos reflexionando respecto a esto, me acuerdo de una conferencia que oí del Profesor David Meybury Lewis, quien trabajó con los Acuashavantes, así como con los Sherentes de la amazonia brasilera. En un momento determinado de su presentación en Harvard, él manifestó, "bueno, ¿y por qué es que estamos luchando por esta gente? ¿Porque son exóticos, porque ya se van a morir, porque el contacto les va a ser de tal naturaleza perjudicial que 
desaparecerán a corto plazo, porque los Garimpeiros van a arrasar con ellos?” Luego de aquella enumeración concluyó: "no, por ninguna de aquellas razones, simple y llanamente porque son tan seres humanos como nosotros, y por desventura parece que nosotros hemos perdido esa perspectiva”.

Entonces, siempre les estamos viendo como seres exóticos, como generadores del problema, cuando es todo lo contrario. Y cualquier tipo de reivindicación, cualquier tipo de contacto y acción, tiene que hacerse con esta base fundamental de que son seres humanos como nosotros y punto. Y por eso tienen derechos, $\mathrm{y}$ tienen necesidad de respeto y de espacios y tiempos propios y de todo aquello que les permita su reproducción tanto biológica como socio cultural. Esa actitud nos permitirá no verlos como trofeos, como por desventura se tiende a considerarlos, como una medalla de oro en los olímpicos, y ese no es el camino, o puede ser el camino. Ni el gobierno ni las ONG's ni de parte de la academia o personas interesadas en el asunto se puede tolerar una actitud de esa naturaleza.

Bueno, Marcelo. Creo que es bien interesante lo que hemos planteado y vamos a terminar acá.

\section{Anne Christine Taylor*}

De una manera convergente con Marcelo Naranjo, la segunda entrevista que presentamos es la de Anne Christine Taylor, quien también nos muestra críticamente algunos problemas con lo que sucede en nuestro país y con la capacidad de la sociedad ecuatoriana para enfrentar estos temas.

Los pueblos en aislamiento voluntario en el Ecuador han vivido situaciones de muy fuerte violencia, en período de más o menos 10 años se han producido verdaderas masacres, a las cuales cabría agregar muertes menos numerosas que se producen intermitentemente. Esto no es la norma entre los casos de los diferentes países en los cuales existen pueblos en aislamiento. Quisiéramos saber isi usted considera que la violencia que se vive en el Ecuador respecto a estos pueblos, es en efecto mayor a otros casos, y si es que es así a que cree usted que esto se debe?

Habría que precisar que en el Ecuador 'los pueblos en aislamiento voluntario' por el momento se reducen a uno - el subgrupo de cultura waorani llamado Tagaeri. Y es cierto que las relaciones entre este grupo y sus vecinos, indígenas como mestizos, han sido y siguen siendo muy violentas. Para explicarlas es pertinente ver varios elementos. El primero es una cuestión de escala: el territorio amazónico del país no es tan extenso como el de Brasil, del Perú o de Colombia, y quedan pocas zonas que no han sido penetradas y ocupadas por empresas extractivas, por grupos indígenas o colonos en búsqueda de tierras, por ONGs y misiones religiosas, etc. En breve, la penetración y presencia del frente de colonización es mucho más marcada aquí que en los países amazónicos vecinos, y por lo tanto la posibilidad de refugiarse en lugares realmente aislados se restringe continuamente.

Otro factor es que otros países, especialmente Brasil y en menos grado Colombia y el Perú, han tenido un largo proceso de desarrollo de instituciones que se han ocupado del tema y que han madurado políticas y procedimientos que permiten actuar respecto a estas situaciones, de maneras que pueden efectivamente controlar la violencia. La FUNAI por ejemplo ha desarrollado no sólo protocolos adecuados sino además capacidades de intervenir y aplicarlos - no siempre para lo mejor pero algunas veces sí. En el Ecuador en cambio vemos una menor tradición institucional, y además un proceso por el cual el tema de los 'pueblos indígenas aislados' es

* Profesora emérita del Centro de Enseñanza e Investigación en Etnología Amerindia de la Universidad de Nanterre. Ex directora del Museo de Quai Branly en París. Investiga las dinámicas históricas de la alta Amazonia. 
tratada con un alto perfil, con mucho apasionamiento, y quienes tienen intereses ideológicos o económicos directamente ligados a estos temas ocupan totalmente la escena pública, sin suficientes mediaciones para establecer espacios de elaboración de una perspectiva de largo plazo, y en la cual los intereses particulares de todo tipo puedan ser efectivamente comparados, debatidos y equilibrados.

Debe pensarse que la relación con los pueblos 'no contactados', que en realidad están en aislamiento por un decisión que tomaron frente a un contacto que sufrieron durante algún tiempo, requiere si entra en crisis de una negociación, casi de tipo westfaliana, en las cuales lentamente todas las partes en conflicto van encontrando formas de disminuir la violencia y a partir de ello desarrollan formas de convivencia.

La Antropología ha elaborado en décadas recientes, algunos conceptos sobre las culturas amazónicas. Por ejemplo los que se refieren a la forma en la cual la violencia es parte y un proceso de construcción identitaria, o por otra parte como los pueblos amazónicos han desarrollado ontologías, es decir formas de comprensión de los seres, que son diferentes y alternativas a las occidentales. ¿En qué medida considera usted que tales elementos pueden ser útiles para comprender y actuar frente a la situación que viven los pueblos no contactados?

En esto creo que hay que ser bastante claro. En primer lugar, no estamos hablando aquí de las formas de violencia 'tradicional' que alimentan los procesos de construcción identitaria. No conozco bien todo este dosier de los enfrentamientos entre los Waorani y los Tagaeri, pero según entiendo, el comportamiento de los Waorani que atacaron a los Tagaeri en el 2013 incluye elementos inéditos, por ejemplo, de visualización, de fotografía, de sus actos que son totalmente fuera del ámbito de enfrentamientos tradicionales. Además, en estos casos el desequilibrio de armamento, de fuerza, es total. Entonces, en ningún caso se puede decir "esto es cultura" y por lo tanto debe ser mantenido por razones de respeto a la diferencia cultural. Claro que como antropóloga defiendo el relativismo cultural como principio metodológico, es decir la necesidad de entender formas distintas de ser en el mundo sin reducirlas a nuestras categorías y modos de acción y entendimiento; pero esto no implica que, a la hora de buscar formas viables de convivencia entre grupos con valores y concepciones distintos, no se debe escoger principios y tratar de lograr un acuerdo sobre su respeto.

No hay que poner el relativismo en el falso ámbito. Ecuador es o quiere ser una república democrática, y no solo un estado plurinacional, y eso obviamente impone límites a la extensión de la autonomía cultural. Entonces hay que negociar formas de convivencia con los Tagaeri, si es que quieren quedarse 'aislados' (y habría que analizar exactamente lo que esta noción involucra). Ahora bien, la dificultad de un ejercicio de diplomacia intercultural/interétnico de este tipo es de impedir que uno de los 'concerned parties' impone sin discusión sus propios valores y su discurso, bajo pretexto que son la expresión del sentido común, de la exigencia de orden público, del desarrollo, de la razón, de la civilización, etc. No hay que partir de supuestos principios universales sino más bien llegar a formas mucho más modestas, locales y contextuales de un 'universalismo relativo', es decir, en este caso, un acuerdo sobre la manera en que diversos grupos van a compartir pacíficamente un cierto territorio y sus recursos. No se puede dejar a las multinacionales, al ejército, a las misiones, a los colonos o a los Huaorani definir ellos solos 'la realidad'. Claro que por el momento la negociación directa con los Tagaeri es (o parece ser) imposible; ellos no van a entender cuál es el problema, cuáles son las posibilidades ofertas por une 'mesa de negociación'. Por lo tanto hay que imaginar formas de representación para ellos, que permiten expresar y defender sinceramente su punto de vista.

De manera general, creo incluso que se debe introducir mediaciones para todas las partes involucradas. En casos de conflictos internacionales, los Estados no negocian directamente, o solamente al final; son los diplomáticos que se encargan de eso. El recurso a 'diplomático' 
tiene muchas ventajas, entre otras la de 'enfriar' situaciones demasiado apasionadas y de dar tiempo a la elaboración de soluciones a largo plazo. Puede parecer utópica la proposición, dado el desmantelamiento de todos los dispositivos de mediación no-estatales a la cual asistimos hoy en día en el Ecuador. Sin embargo, si tomamos realmente en serio los dos principios fundamentales de la constitución ecuatoriana - un régimen republicano y democrático, una nación étnica y culturalmente plural- este tipo de comisión - de mini-constituyente, para decirlo así - debería ser mucho más común y 'banal' en la vida política del país que no lo es. Es una lástima: el Ecuador tendría aquí la oportunidad de tomar une posición innovadora y ejemplar en el campo de la invención de formas realmente justas de convivencia entre grupos culturalmente diversos, es decir que tienen modos de vida y modos de utilizar los recursos de su entorno bien distintos.

Como te dije, yo no estoy al tanto de toda la situación regional en torno al drama tagaeri y, por lo tanto, es difícil para mí opinar sobre ella. Pero no veo otra solución que la creación de una especie de comisión cuyos miembros serian a igual distancia de todos los partidos 'demasiado interesados' en toda esta tragedia. Y por 'demasiado interesados', quiero decir precisamente el ejército, el Estado ecuatoriano, los Waorani y los colonos, cada uno empeñado por el momento en imponer su visión de la situación. Los únicos que no escuchamos en esa cacofonía son los Tagaeri. Concretamente, creo que una comisión de este tipo debería incluir representantes de cada 'partido', incluyendo un representante/abogado de los Tagaeri (podría ser un colectivo de antropólogos, juristas, eclesiásticos...), a más de observadores internacionales. El rol de esta comisión seria negociar poco a poco una forma de autonomía para los Tagaeri, si es que quieren quedarse aislados, es decir, una nueva forma de convivencia con ellos que sea aceptable para todas las partes involucradas, incluso los colonos, lo que supone que los Tagaeri dejen de matar o de atacar a colonos y a Waorani, lo mismo al revés. Que se delimite territorios en los que no pueden penetrar ni Waorani ni colonos ni empresas extractivas ni militares, etc., para que los Tagaeri puedan seguir cazando, etc. Esta comisión debería también prever definir los medios que permitirían imponer los términos del acuerdo y reprimir su transgresión.

Quisiera hacerle una última pregunta. Hemos visto, que en la Antropología Amazónica especialmente, se ha hecho una reflexión importante sobre cómo existen, lo que podríamos llamar distintos procesos de creación de la conciencia del ser humano respecto a la naturaleza. La comprensión de estos procesos, ¿cree usted que tienen un rol particular para poder entender la situación de estos pueblos en aislamiento o no es tan fundamental?, o ¿en qué manera cree usted que esas concepciones del ser, esas ontologías, pueden estar influyendo o es necesario entenderlas para poder avanzar en esa negociación?

Mira, para decir las cosas de manera un poco grosera, dos cosas: primero, yo no creo que sea necesario movilizar este tipo de instrumentos de análisis para entender o incluso para determinar una línea de conducta para con los Tagaeri. Francamente, yo creo que basta una verdadera adhesión a valores de respeto a la auto-determinación que se concede a colectivos humanos - o que se debería conceder a cualquier grupo humano. Claro que un buen conocimiento antropológico de la manera en que grupos como los Tagaeri ocupan un territorio y explotan sus recursos es necesario al momento de negociar un acuerdo de convivencia, del mismo modo que un cierto conocimiento de su mundo intelectual es necesario para manejar los varios niveles de traducción - lingüística y cultural - inherentes a este tipo de negociación. Pero a mi juicio lo más importante es sencillamente tomar en serio lo que dicen los Tagaeri - exactamente al mismo nivel que tomamos en serio el discurso más familiar de las instituciones estatales, de los colonos, de los petroleros, etc.

En segundo lugar, lo que sí me parece útil es la reflexividad crítica que permite el tipo de análisis del cual tú acabas de hablar, es decir, análisis de tipo ontológico, digamos, sobre la manera en que grupos indígenas se relacionan con la naturaleza, etc. Yo creo que lo que sí es 
mucho más necesario que una comprensión o un análisis antropológico de la ‘cosmovisión' de los Tagaeri es más bien un análisis antropológico de la posición nuestra en esta situación, y de manera general de la situación en su conjunto - la antropología está ahora bastante bien armada para analizar situaciones de controversia y de conflictos de valores y entendimientos.

Mejor hacia adentro, o sea cómo esa visión nos permite ver qué es lo que estamos haciendo nosotros y cómo estamos funcionando nosotros. Ahora, en cierta medida, tú estuviste planteando algo que creo que nos podría llevar a decir: el principal problema de los Tagaeri es el de la dinámica de las sociedades que están alrededor de ellos. Y ahí, probablemente uno de los temas más difíciles de manejar es que, esas sociedades, tanto los colonos como también los Waorani, tienen una dinámica de expansión. Tienen presiones por las cuales deben expandirse. El proceso especulativo de los colonos está más o menos documentado, el caso de los Waorani tiene una dificultad especial, y es que ellos están viviendo un recorte de sus recursos y entonces su respuesta es expandirse a una explotación de mayor área que les lleva al conflicto.

Es cierto que la presión demográfica y la explotación demasiado intensiva de los recursos selváticos es un factor central. Es precisamente por esta razón que se vuelve imprescindible la negociación de un pacto de uso del espacio selvático y de convivencia entre los varios grupos que comparten esa zona. Sino siempre van a seguir estas tragedias hasta que los Tagaeri o sean totalmente exterminados, o incorporados de bueno o mal gana a la sociedad Waorani. Y no son los Tagaeri los únicos a ser tratados de manera injusta en esta parte de la Amazonia: los colonos pobres sufren al igual que los indígenas de la contaminación ambiental, de la explotación de su mano de obra, de la pérdida de sus terrenos y de su capacidad a sustentar une vida decente. A ellos también una negociación general ofrecería una oportunidad para mejorar su situación. Pero hay que hacerlo seriamente, es decir, dando un status de interlocutor de igual magnitud, de igual peso, a todas las partes involucradas, incluso a los Tagaeri o mejor dicho a los que pueden pretender, con legitimidad o credibilidad, representarlos y defender sus intereses. Muchas Gracias.

\section{Laura Rival*}

La tercera y última entrevista, es aquella que proviene de una experiencia y cercanía mayor al tema de los Tagaeri. Laura Rival nos muestra, no solamente una perspectiva muy actual e informada sino que además nos habla de dos aspectos adicionales. Por una parte de como su visión ha evolucionado. Nos describe como el proceso de acercarse y comprender está realidades exige, como todo esfuerzo antropológico, una disposición a cambiarnos a nosotros mismos. Veamos lo que ella nos dice. Pero también nos aporta con perspectiva de cómo estos temas están siendo tratados, en otros países: (Brasil y Colombia) así como también algunas útiles referencias a otros trabajos académicos en Londres. Todo ello con el matiz de su propio estilo, de la riqueza de sus polémicas, debates y apasionamientos. Laura contestó la entrevista en inglés, la traducción es del entrevistador.

Como mencione en mi correo electrónico previo. Prefiero escribir en inglés para asegurarme de que mi pensamiento vaya con todos sus matices, me voy a permitir contestar las preguntas sin necesariamente seguir el formato de cuatro partes ya que ellas se superponen al menos en parte.

También quisiera agregar que las razones que tengo para involucrarme en este ejercicio tienen mucho que ver con lo que yo entiendo como mi compromiso como una antropóloga profesional, así como con el verdadero afecto y aprecio que he sentido durante toda mi vida por el Ecuador,

* Profesora de la Universidad de Oxford, en el Instituto de Antropología Social y Cultural. Sus investigaciones de larga data alrededor del grupo indígena Huaorani se han materializado en más de 20 publicaciones sobre el tema. 
mi país de adopción en cierto sentido a pesar de que existe una cierta tensión entre estas dos motivaciones. Si yo fuera ecuatoriana o si viviera permanentemente vería las cosas de manera diferente. Esta diferencia va más allá de la tensión entre antropología aplicada y académica, las mismas que a la final se disuelven en distinciones superficiales y artificiales. Existe una antropología desde adentro que tiene que ser diferenciada de la antropología desde afuera. Estoy convencida que es la interacción entre estas dos antropologías lo que da a la disciplina su razón de ser (raison d'être). Es por esta razón que soy bastante cínica respecto al trabajo que algunos de mis jóvenes colegas realizan desde el Reino Unido. Surge en mi mente alguien como Maertin Holbraad, así como toda la saga ontológica generada en Cambridge. La tensión creativa entre las antropologías desde dentro y desde fuera varía también en cada contexto cultural. Cuando pienso en el Ecuador siempre comparo (más o menos conscientemente) la situación del Ecuador con otros dos contextos antropológicos latinoamericanos que mejor conozco además del ecuatoriano, los de Brasil y Colombia.

\section{Pueblos en aislamiento voluntario y el conocimiento antropológico}

Las preguntas se refieren a cómo categorizar a pueblos como los Taromenani y cómo la definición y categorización de estos pueblos tanto como la descripción de sus costumbres podrá eventualmente contribuir al desarrollo del conocimiento antropológico. Se trata de una gran pregunta debatida encendidamente entre los amazonistas. Como se podrá dar cuenta estamos muy lejos de tener un acuerdo sobre este tema. Incluso más allá de eso la generación más joven de antropólogos parece llegar al extremo de ver el "aislamiento voluntario" como un estereotipo occidental, un peligroso artificio del derecho internacional y así en esa misma perspectiva. Estos jóvenes colegas ven a la domesticación y a la desigual incorporación de lo que ellos ven como los remanentes de la historia como algo inevitable.

No es necesario aclarar que estoy en un profundo desacuerdo con su posición, que considero que proviene de una vinculación poco informada con las realidades económicas y políticas. La mayor parte de los grupos aislados están localizados en la cuenca amazónica y existen algunas consideraciones económicas y políticas más generales que deben ser consideradas además de las especificidades del desarrollo amazónico en los siglos XX y XXI.

Algunos colegas tienden a ver este asunto en términos puramente humanitarios, y destacan los riesgos de salud asociados al contacto. Yo no me he propuesto tomar una posición respecto a estos temas de derechos humanos y me he enfocado a las especificidades del caso Waorani/ Taromenani. He tenido intensos intercambios con un joven colega brasilero, Felipe Milanez, quien ha escrito extensamente sobre la situación de los pueblos no contactados en la Amazonía brasilera. También he debatido estos temas con científicos sociales y activistas ecuatorianos, respetando en ello el hecho de que las políticas deben ser conceptualizadas y diseñadas por los propios ecuatorianos

El Ecuador ha creado una legislación muy progresista en este tema (como en otros) pero no en todas las ocasiones ha podido avanzar en su aplicación. Entiendo que esto es un tema para un debate de los ecuatorianos, a fin de cuentas es en sí mismo un asunto más político que específicamente antropológico. Como lo digo con frecuencia a las personas que me piden asesoría "no se necesita un antropólogo para que te diga que el gobierno está violando sus propias leyes".

Desde una perspectiva puramente antropológica puede también exacerbar el riesgo de escencializar la situación de no contactados. En términos de teoría antropológica la persistencia hasta el día de hoy de pequeños grupos no contactados ilustra bien algunos aspectos únicos de la etnohistoria indígena amazónica, incluyendo aspectos filosóficos relacionados con la conceptualización de aquello que es humano y lo que no lo es, sin que se trate de fuentes únicas o exclusivas sobre este último punto. En el Ecuador como en el Brasil la existencia de estos grupos es un tema importante en la formación de la identidad nacional, especialmente en cuanto cuestionadoras de las formas modernistas de la identificación social política y cultural. Para 
los ciudadanos jóvenes personas como los Taromenani amplían el imaginario hacia formas alternativas de identidad social. Esto permite que las personas, (incluidos los Científicos Sociales) dejen a un lado, de una vez por todas, el evolucionismo del siglo XIX y especialmente las ideas de progreso y civilización.

\section{Waorani/ Taromenani, transformación histórica y violencia}

He experimentado la realidad de la existencia de hombres, mujeres y niños taromenani en términos de una conciencia renovada de mis propios sesgos. Esto se relaciona con el hecho de asumir que existía algo en mis propios presupuestos que me impedía aceptar la existencia "real" hasta que Babe capturo a esa muchacha. Pero ahora estamos hablando de toda una generación de Waorani, Tagaeri y Taromenani que han co-existido en la frontera petrolera. Esto plantea una serie de preguntas en términos de historia, cambio y transformaciones que tienen que ser mejor manejadas, especialmente a la luz de los cambios mayores que han ocurrido en el Ecuador y en el conjunto de la cuenca amazónica durante este período. Los científicos sociales ecuatorianos necesitan pensar colectivamente sobre el impacto de la industria petrolera en la región y en la cultura nacional.

Una cosa es clara y debe ser recordada permanentemente. La relación entre waorani y Taromenani no ha sido siempre ni necesariamente de violencia. Los waorani de Bameno, por ejemplo han mantenido una relación de convivencia pacífica con estos grupos por un largo período de tiempo. Los de la carretera de la Maxus, no lo han hecho. Los waorani de Bameno se han transformado históricamente de manera sustancialmente diferente a los de la vía Maxus. Si las mujeres y los niños han sido las víctimas principales entre los Taromenani, ésto se relaciona más con la táctica de la retaliación impuesta por la frontera petrolera que con las esencias de las ontologías culturales ligadas a la violencia y la guerra.

Mi interpretación de la cultura waorani es necesariamente tentativa, evoluciona con el tiempo y es necesariamente parcial. Las interpretaciones antropológicas pertenecen al discurso académico. Lógicamente se basan en las realidades culturales descritas, pero el conocimiento etnográfico no es un conocimiento. Aún más, la sociedad waorani ha cambiado y se ha transformado de manera dinámica y heterogénea en los últimos treinta años. Si una parte de mi trabajo da la impresión de fijar la cultura waorani en un presente etnológico me excuso, esta no fue la intención. El estudio de la tradición oral waorani indica que sí que la guerra es un componente crucial de la autonomía y del establecimiento de fronteras y como tal de la reproducción social y política. De todas maneras no hay nada automático o mecánico en la reproducción de la violencia (¿Es esto lo mismo que la guerra?) Muchos hombres waorani han dejado a un lado la violencia, como Casey High lo ha mostrado. Más aún las situaciones de violencia, nueva y antigua se expresan de manera dialéctica y relacional. Los hombres de la vía Maxus (principalmente los baiberi y los wepiri) no son estructural o intrínsecamente violentos. Es en la situación de la frontera petrolera que ellos han (re) producido ciertas formas de comportamiento político violento. Tal violencia puede ser intrínsecamente diferente de las formas tradicionales de violencia. Lo que pretendo decir es que la violencia tradicional está siendo reproducida en un contexto contemporáneo que involucra profundamente a la sociedad y a la cultura nacional.

\section{EI trabajo antropológico y las políticas públicas}

Esto me lleva a alertar sobre el peligro de cualquier fácil traducción del conocimiento antropológico hacia las políticas públicas. En América Latina se desarrolla actualmente un debate sobre la justicia indígena y la ciudadanía, respecto a lo cual cabe mencionar el trabajo de Rachel Sieder. Enfrentados desde el año 2013 con una seria crisis los waorani están en el proceso de dotarse de nuevas reglas. Su percepción de la sociedad nacional está cambiando rápidamente. Han sentido la fuerza del Estado por primera vez, tanto como los derechos 
y obligaciones de la ciudadanía ecuatoriana. No he hablado con los hombres que fueron encarcelados, ni con sus familias, y por lo tanto no sé cómo han internalizado estos cambios. Un ex-alumno mío, Harry Walker, que actualmente se encuentra en el London School of Economics, especialista en los Urarina del Perú, precisamente se ocupa actualmente de las transformaciones que están sucediendo en las sociedades amazónicas una vez que el Estado llega a ellas. Se trata de un tema importante, pero lamentablemente todavía muy incipiente y en el cual no tengo competencia.

Sospecho que el desafío será como siempre, el de evitar, por una parte, la sobre generalización o sobre universalización de determinadas respuestas locales al Estado y del otro lado evitar cualquier forma de esencialización de esas respuestas. Los dinámicos procesos de transformación histórica que están sucediendo representan un desafío, no sólo para la teoría, sino también para la gestión. No van a existir respuestas simples, pero hay algo que es claro. Tales situaciones de contacto son dinámicas y relacionales, y por lo tanto nunca podrá tratarse de simplemente encontrar las mejores leyes posibles para "administrar" al otro salvaje sino más bien una tarea de re trabajar las leyes y las nociones de ciudadanía al interior de un estado-nación plurinacional. Los taromenani nos deben cambiar a todos, a los waorani, a los ecuatorianos y a los no ecuatorianos.

Me doy cuenta de que nada de lo que he dicho representa una indicación clara sobre cómo elaborar mejores política en el Ecuador, pero siempre he sido del criterio de que la antropología no puede ser aplicada de esa manera. Solamente puede informar para una comprensión más profunda del significado de quienes somos como seres humanos y ciudadanos de países particulares.

En el Ecuador, hay todavía mucho paternalismo en relación a los ecuatorianos indígenas, Un excesivo sentimiento de que son inferiores y que necesitan medidas civilizatorias. El debate ha avanzado más en el Brasil, por lo menos entre los intelectuales y los antropólogos han tenido un rol crucial para enriquecer las deliberaciones públicas sobre la identidad nacional. Una vez que hemos señalado esto, el rol de los antropólogos en los proceso de política pública no se ha hecho más fácil por el reconocimiento de la diversidad y riqueza cultural. Todo el trabajo desarrollado por los colegas brasileños en colaboración con antropólogos europeos por ejemplo sobre las relaciones entre la diversidad biológica y cultural, han informado las políticas de preservación cultural, por ejemplo aquellas aprobadas en el río Negro. De todas maneras esas medidas no han impedido la pauperización de los indígenas, su marginalización el racismo y otras formas de desigualdad.

1 El original dice: to police de savage, que puede corresponder al antiguo uso castellano de dar policía a una población. 
